\section{Case Report}

Korean J Transplant 2021;35:59-65 https://doi.org/10.4285/kjt.20.0038

\section{$\mathrm{KJT}$ \\ KOREAN JOURNAL OF TRANSPLANTATION}

\title{
Pediatric liver transplantation using a hepatitis B surface antigen-positive donor liver graft for congenital absence of the portal vein
}

\author{
Jung-Man Namgoong ${ }^{1}$, Shin Hwang ${ }^{1}$, Dae-Yeon Kim¹, Tae-Yong Ha ${ }^{1}$, Gi-Won Song ${ }^{1}$, \\ Dong-Hwan Jung ${ }^{1}$, Kyung Mo Kim², Seak Hee Oh${ }^{2}$
}

${ }^{1}$ Department of Surgery, Asan Medical Center, University of Ulsan College of Medicine, Seoul, Korea

${ }^{2}$ Department of Pediatrics, Asan Medical Center, University of Ulsan College of Medicine, Seoul, Korea

Received September 4, 2020

Revised October 1, 2020

Accepted October 2, 2020

Corresponding author: Shin Hwang Department of Surgery, Asan Medical Center, University of Ulsan College of Medicine, 88 Olympic-ro 43-gil, Songpa-gu, Seoul 05505, Korea Tel: +82-2-3010-3930

Fax: +82-2-3010-6701

E-mail: shwang@amc.seoul.kr

(c) The Korean Society for Transplantation This is an Open Access article distributed under the terms of the Creative Commons Attribution Non-Commercial License (http://creativecommons.org/licenses/ by-nc/4.0/) which permits unrestricted non-commercial use, distribution, and reproduction in any medium, provided the original work is properly cited.
Congenital absence of the portal vein (CAPV) is a rare venous malformation in which mesenteric venous blood drains directly into systemic circulation. Herein, we report a case of pediatric deceased donor liver transplantation (DDLT) for symptomatic CAPV with whole liver graft from a hepatitis B surface antigen (HBsAg)-positive donor. A 4 -year-old boy suffered from CAPV and secondary portal hypertension. He was also diagnosed with DiGeorge syndrome and heart anomalies. After waiting for 4 months, a 5-year-old donor weighing $19 \mathrm{~kg}$ with positive HBsAg was allocated to this 4-year-old patient weighing $15 \mathrm{~kg}$. Recipient operation was performed according to the standard procedures of pediatric DDLT. Portal vein reconstruction was performed using interposition of a vascular homograft conduit to the superior mesenteric vein-splenic vein confluence. The patient recovered uneventfully from DDLT. He has been administered with lamivudine to prevent hepatitis $B$ virus infection. This patient has been doing well for 5 years after DDLT without growth retardation. In conclusion, CAPV patients can have various vascular anomalies, thus combined vascular anomalies should be thoroughly assessed before and during liver transplantation operation. The most effective reconstruction techniques should be used to achieve satisfactory results following liver transplantation.

Keywords: Portal vein agenesis; Portacaval shunt; Portal hypertension; Hepatitis B virus; Preemptive therapy

\section{INTRODUCTION}

Congenital absence of the portal vein (CAPV) is a rare venous malformation in which the mesenteric venous blood drains directly into the systemic circulation. The majority of patients with CAPV show no signs or symptoms of portosystemic encephalopathy. They only show slightly abnormal liver function tests. Liver transplantation (LT) is indicated for patients with symptomatic CAPV refractory to medical treatments [1], especially those with hyperammonemia, portosystemic encephalopathy, hepatopulmonary syndrome, hepatic tumors, or intractable complications.

The congenital portocaval shunt (PCS) drains all mesenteric venous blood either directly into the inferior vena cava (IVC) or the left renal vein. Thus, theoretically there is 


\section{HIGHLIGHTS}

-We report a case of successful pediatric deceased donor liver transplantation for symptomatic congenital absence of the portal vein with whole liver graft from a hepatitis $B$ surface antigen-positive donor.

- This patient has been doing well for 5 years after transplantation without growth retardation.

no portal hypertension or collateral circulation [2]. The liver with CAPV does not have sufficient portal inflow, thus the hepatic arterial flow is the main inflow blood. If a patient cannot tolerate a medical treatment, LT should be taken into account. Although CAPV induces various clinical manifestations, liver function profiles of patients with CAPV are not severely impaired. Their Pediatric End-stage Liver Disease scores remain low. Since pediatric patients with CAPV do not have any priority in the waiting list, they have a very low chance of receiving deceased donor liver transplantation (DDLT). Herein, we present a case of pediatric DDLT for symptomatic CAPV with a whole liver graft from a hepatitis B surface antigen ( $\mathrm{HBsAg}$ )-positive pediatric donor.

\section{CASE REPORT}

The study protocol was approved by of the Institutional Review Board at Asan Medical Center (IRB No. 2020-0836), which waived the requirement for informed consent due to the retrospective nature of this study.

A 4-year-old boy was referred due to melena and hematochezia. He was born through a normal full-term delivery. At birth, cardiac murmur was identified. His ventricular and atrial septal defects were increased during a short-term observation. Thus, repair operation was performed at 40 days after birth. Seven days later, he underwent bilateral inguinal hernia operation. At 1 year of age, he underwent anoplasty for abnormal location of anus to the rectum. At 3 years of age, he received supportive care for esophageal and gastric varix bleeding. Serum ammonia level was within the normal limit. At 4 years of age, he underwent endoscopic varix ligation to control melena and hematochezia. Computed tomography showed agenesis of the portal vein with cavernous transformation and secondary portal hypertension with gastric and esophageal varix (Fig. 1). Liver function test findings were still normal. He was diagnosed with mild tricuspid regurgitation. He was also diagnosed with DiGeorge syndrome (microdeletion 22q11.2). However, other significant anomalies were absent except heart disease and CAPV. This patient was not indicated for Rex shunt
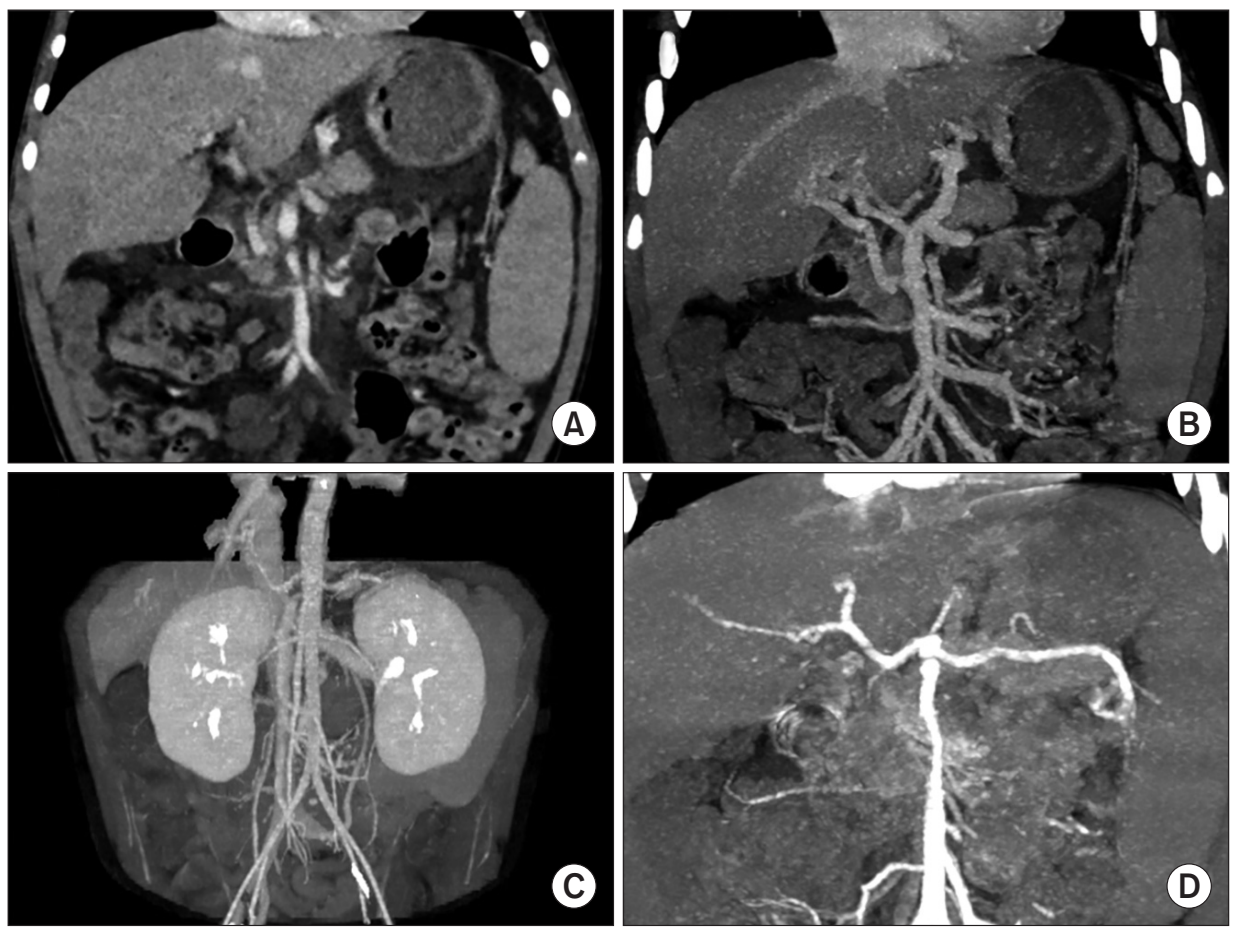

Fig. 1. Pretransplant computed tomography scan. (A-C) There is agenesis of the portal vein with cavernous transformation and secondary portal hypertension with gastric and esophageal varix. Any large communication vein to the inferior vena cava or left renal vein is not visible. (D) The anatomy of the hepatic artery appears to be normal. 
operation because of poor development of the intrahepatic portal vein system. Thus, we decided to perform LT.

After waiting for 4 months in the pediatric waiting list, a 5-year-old donor weighing $19 \mathrm{~kg}$ with positive HBsAg was allocated to this 4-year-old patient weighing $15 \mathrm{~kg}$. Liver function test findings of the deceased donor were not highly impaired and significant pathological abnormality was not present on frozen-section liver biopsy. Thus, we decided to use this marginal liver graft because the patient had a very low chance to be allocated for DDLT later. The whole liver graft weighed $580 \mathrm{~g}$ and the graft-recipient weight ratio was $3.9 \%$.

Recipient operation was performed according to the standard procedures of pediatric DDLT. The recipient's native portal vein was absent. Thus, the portal collateral branches at the hepatoduodenal ligament were deeply dissected to fully expose the superior mesenteric vein-splenic vein confluence. After deep clamping of this confluence portion with a Satinsky clamp, an external iliac vein segment harvested from the liver donor was anastomosed to the confluence in an end-to-side fashion (Fig. 2).

We used a modified piggyback technique making a large cavocaval anastomosis to secure graft outflow vein reconstruction. Graft portal vein was reconstructed with the interposed vein conduit. Surgical microscopy was used for hepatic artery reconstruction. Roux-en-Y hepaticojejunostomy was used for biliary reconstruction. Coronary collaterals inducing gastric and esophageal varices were ligated. The pathology report of the explant liver showed increased vascularity with variable shapes of portal venous structures and intimal fibrosis, which were compatible with the characteristics of CAPV (Fig. 3). Permanent wedge biopsy of the graft liver showed subcapsular and perivenular hepatic necrosis with minimal fatty change and absence of portal inflammation and cholestasis.

The patient recovered uneventfully from the DDLT operation. The reconstructed portal vein maintained well without any hemodynamic abnormalities (Figs. 4 and 5). Clinically suspected acute cellular rejection occurred at 2 weeks after transplantation. It responded well to a steroid pulse therapy. The patient had antibody to HBs through scheduled hepatitis B virus (HBV) vaccination before LT. During the early posttransplant period, a combination therapy of hepatitis $B$ immunoglobulin (HBIG) and lamivudine was used to prevent reactivation of HBV. HBIG 10,000 IU was administered every week during the first month and every month during the next 4 months with a target trough level of $1,000 \mathrm{IU} / \mathrm{mL}$. After 6 months after LT, lamivudine monotherapy was used to prevent HBV infection because of high maintenance of anti-HBs titers. His HBsAg and blood HBV DNA were negative up to date. This patient has been doing well for 5 years after LT without any growth retardation.
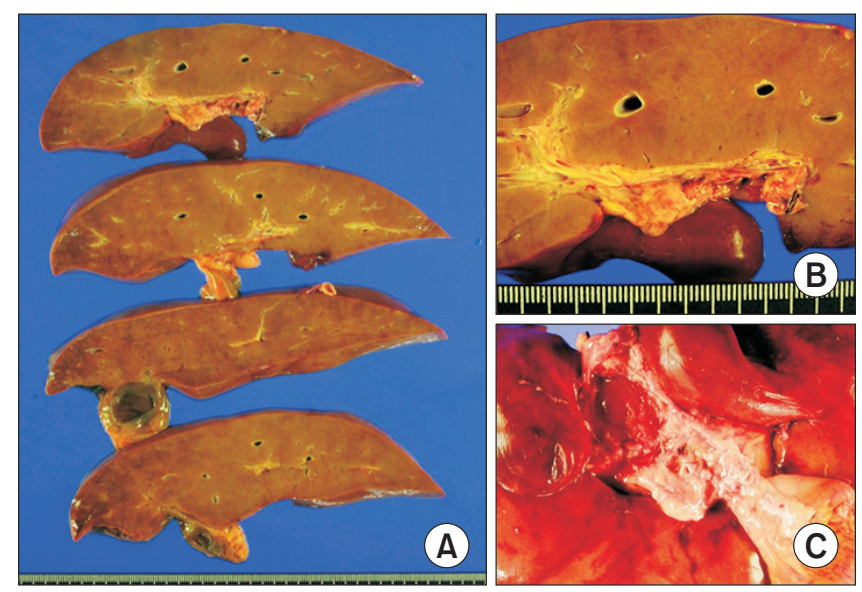

Fig. 3. Gross photographs of the explant liver. (A) The liver parenchyma does not show cirrhotic changes. $(B, C)$ Magnification of the portal triad area shows increased vascularity of portal venous structures with variable shapes and intimal fibrosis.
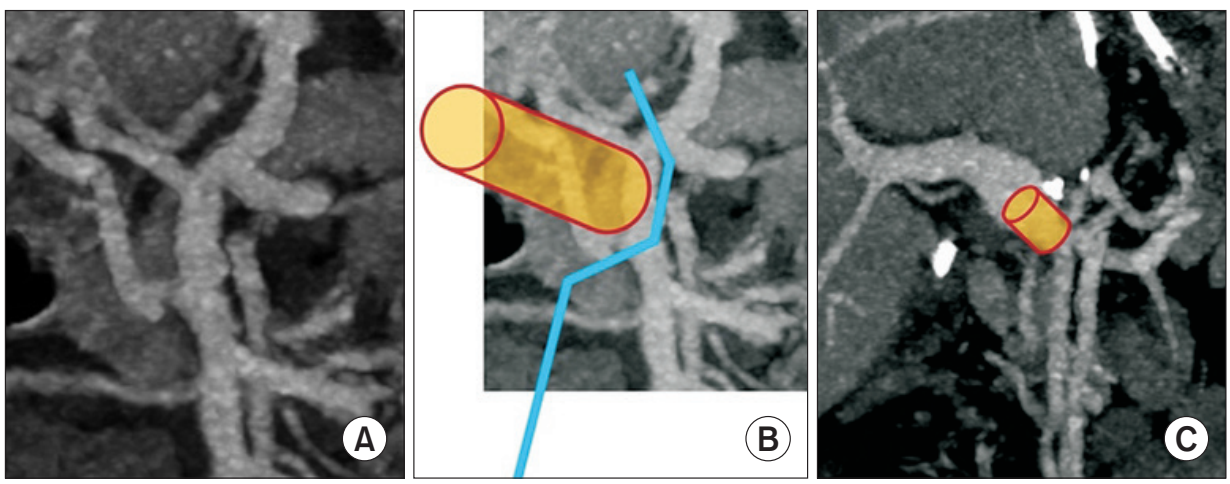

Fig. 2. Surgical technique of end-to-side conduit vein interposition. (A) Anatomy of the superior mesenteric vein-splenic vein confluence is visualized. (B) An external iliac vein graft (cylinder) was anastomosed to the superior mesenteric vein-splenic vein confluence after deep clamping of this confluence portion (blue line). (C) The interposed vascular conduit (cylinder) is located between the superior mesenteric vein-splenic vein confluence and graft portal vein. 


\section{DISCUSSION}

CAPV is a rare venous malformation in which mesenteric venous blood drains directly into the systemic circulation. There are two types of congenital PCS: intrahepatic PCS and extrahepatic PCS. Intrahepatic PCS is detected between portal and hepatic veins [3]. Extrahepatic PCS is divided into type I and type II according to intrahepatic portal venous supply [4]. Type I PCS is an extrahepatic shunt without patent intrahepatic portal vein. Thus, the entire mesenteric venous blood drains directly into a systemic vein such as the IVC or the left renal vein. This type is called CAPV. CAPV can be further subclassified into type la (superior mesenteric vein and splenic vein do not

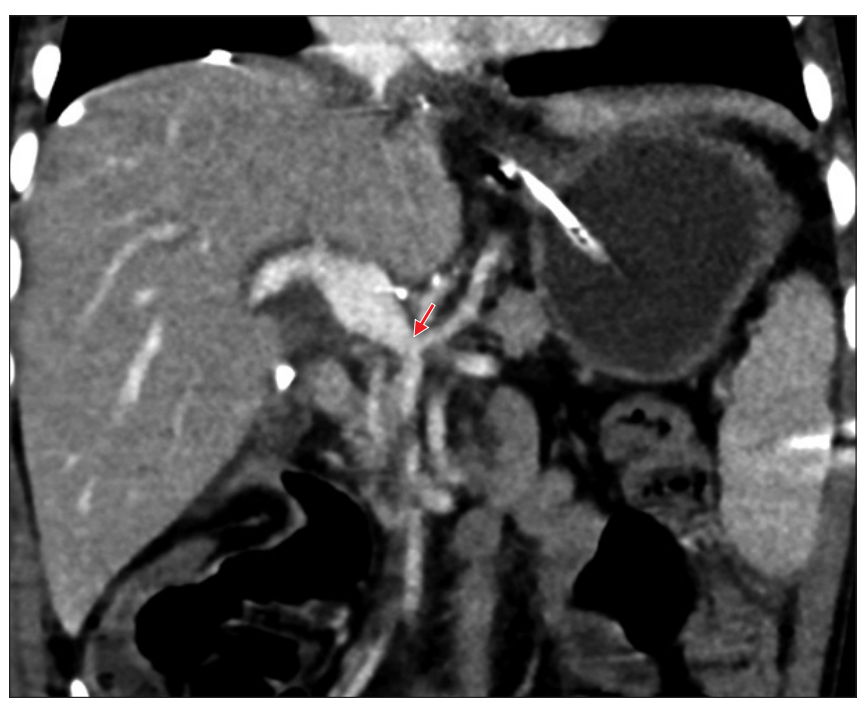

Fig. 4. Posttransplant computed tomography scan taken at 7 days after transplantation. The portal vein reconstruction appears to be smooth streamlined with resolution of variceal collaterals. An arrow indicates the anastomosis site of the interposed vascular conduit and the superior mesenteric vein-splenic vein confluence. join to form confluence) and type $\mathrm{lb}$ (superior mesenteric vein and splenic vein join to form confluence). If the portal vein presents a lack of complete development, the PCS is either the result of the persistence of the right vitelline vein (in which case the shunt connects to the retrohepatic IVC), or of the persistence of the left vitelline vein (the shunt is connected to the IVC or the right atrium above the confluence of the hepatic veins) [5]. Type II PCS is an extrahepatic shunt with patent intrahepatic portal vein. Thus, the patent portal vein perfuses the liver and the shunt vessel drains some mesenteric venous blood into the systemic circulation. Our patient had type la PCS because no portal venous structures were observed in portal triads.

The standard treatment for CAPV has not been established yet. Although PCS can be accompanied by hyperammonemia, the majority of patients with PCS have no signs of encephalopathy. They only show slightly abnormal results in liver function tests. These findings suggest that the development of portosystemic encephalopathy depends on the presence of portosystemic shunting as well as other additional factors, including insufficient reserve of the liver to detoxify ammonia and/or a decline in neurologic tolerance to hyperammonemia. Therefore, many patients with CAPV receive conservative medical treatment for hyperammonemia. Only a small portion of patients with CAPV require surgical treatments including LT. Surgical treatment is indicated when hyperammonemia or portosystemic encephalopathy is refractory to medical treatment. Surgical treatment for CAPV can also be indicated for hepatopulmonary syndrome [6]. CAPV is a venous malformation in which mesenteric venous blood drains directly into the systemic circulation, thus it might be accompanied by hepatopulmonary syndrome.

Unlike usual symptomatic cases with CAPV in the literature, our patient had portal hypertension with gastric and esophageal varix that might be associated with poor devel-
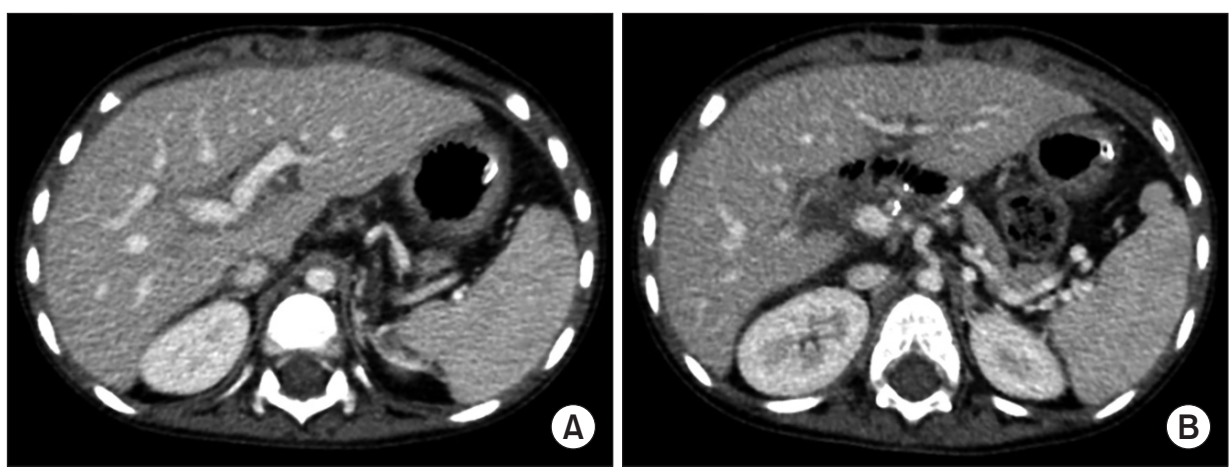

Fig. 5. Posttransplant computed tomography scan taken at 1 month after transplantation. (A) The intrahepatic portal vein appears normal. (B) The extrahepatic portal vein is fully expanded with collapse of the collateral veins. 
opment of congenital PCS. Pretransplant imaging studies showed absence of large communication vein to the IVC or the left renal vein. Variceal bleeding secondary to portal hypertension was the primary cause for our patient to undergo LT.

The strategy of surgical treatment for CAPV depends on the types of PCS. Most patients with type II PCS can be treated by ligating or banding shunt vessels while monitoring the portal pressure to avoid the induction of portal hypertension. In contrast, if the intrahepatic portal vein is immature, LT may be required. In other words, most patients with type I PCS are indicated for LT because surgical reconstruction of portal vein structures of the native liver is impossible, like in our patient.

Although LT for symptomatic CAPV has been reported in the literature, the techniques for portal vein reconstruction have not been well established yet. There are two methods of portal vein reconstruction in LT for CAPV. The first method is to anastomose the PCS directly to the graft portal vein in an end-to-end fashion [1]. The second method is to use a venous interposition graft through an end-toside anastomosis to the PCS [2]. Our patient did not have large shunt vein to directly use it for portal vein reconstruction. Thus, the first method was technically impossible. We have accumulated experience of using the second method for pediatric patients with biliary atresia and portal vein hypoplasia [7]. Thus, we applied the second method to our patient. We summarized the reported cases of LT for CAPV in Table 1 [8-14].

A congenital PCS drains all mesenteric venous blood either directly into the IVC or into the left renal vein. Thus, there is no portal hypertension or collateral circulation. Significant splanchnic congestion may occur when a PCS is totally clamped during portal vein reconstruction, resulting in severe bowel edema and hemodynamic instability. We have previously experienced a similar situation during

Table 1. Summary of the reported cases of liver transplantation for congenital absence of the portal vein

\begin{tabular}{|c|c|c|c|c|c|c|c|}
\hline No. & Study & $\begin{array}{l}\text { Age } \\
\text { (yr) }\end{array}$ & Sex & $\begin{array}{l}\text { Type of } \\
\text { shunt }\end{array}$ & $\begin{array}{l}\text { Indication } \\
\text { for LT }\end{array}$ & $\begin{array}{c}\text { Type of } \\
\text { liver graft }\end{array}$ & Outcome \\
\hline 1 & Matsuura et al. (2010) [8] & 18 & Female & $\begin{array}{l}\text { PSS between SMV and } \\
\text { RIIV via IMV }\end{array}$ & $\begin{array}{l}\text { Mild encephalopathy and } \\
\text { general fatigue due to } \\
\text { persistent hyperammonemia }\end{array}$ & $\begin{array}{l}\text { APOLT LDLT } \\
\text { with LL }\end{array}$ & Alive, 3 months \\
\hline 2 & Law et al. (2011) [9] & 5 & Female & $\begin{array}{l}\text { PSS between convergence } \\
\text { of SMV and SV and } \\
\text { azygos vein }\end{array}$ & HPS & $\begin{array}{r}\text { Split DDLT } \\
\text { with LLS }\end{array}$ & $\begin{array}{l}\text { Died after } 2 \text { years } \\
\text { due to chronic } \\
\text { rejection }\end{array}$ \\
\hline 3 & Uchida et al. (2012) [10] & 14 & Male & $\begin{array}{l}\text { PV directly drain to IVC; } \\
\text { SMV and splenic vein do } \\
\text { not join to form confluence }\end{array}$ & HPS & $\begin{array}{l}\text { LDLT } \\
\text { with LL }\end{array}$ & Alive, 3 years \\
\hline 4 & Gordon-Burroughs et al. (2014) [11] & 61 & Female & $\begin{array}{l}\text { PV directly drain to IVC; } \\
\text { SMV and splenic vein } \\
\text { join to form confluence }\end{array}$ & $\begin{array}{l}\text { Recurrent HCC post left } \\
\text { hepatectomy }\end{array}$ & DDLT & Alive, 3 years \\
\hline 5 & Brasoveanu et al. (2015) [12] & 21 & Female & $\begin{array}{l}\text { PV directly drain to IVC; } \\
\text { SMV and splenic vein } \\
\text { join to form confluence }\end{array}$ & $\begin{array}{l}\text { Unresectable hepatocellular } \\
\text { adenoma }\end{array}$ & $\begin{array}{l}\text { LDLT } \\
\text { with LL }\end{array}$ & Alive, 9 months \\
\hline 6 & Li et al. (2020) [13] & 29 & Male & $\begin{array}{l}\text { IMV shunts through SV } \\
\text { into IVC }\end{array}$ & HPS & $\begin{array}{l}\text { LDLT } \\
\text { with RL }\end{array}$ & $\begin{array}{l}\text { Died after } 3 \text { months } \\
\text { due to sepsis }\end{array}$ \\
\hline 7 & Matsumoto et al. (2020) [14] & 7 & Female & SV drained into IVC & HPS & $\begin{array}{l}\text { LDLT } \\
\text { with LL }\end{array}$ & Alive, 2 months \\
\hline 8 & This study & 4 & Male & $\begin{array}{l}\text { No large communication } \\
\text { vein to IVC or LRV }\end{array}$ & Varix bleeding & DDLT & Alive, 5 years \\
\hline
\end{tabular}

LT, liver transplantation; PSS, portosystemic shunt; SMV, superior mesenteric vein; RIIV, right internal iliac vein; IMV, inferior mesenteric vein; APOLT, auxiliary partial orthotopic liver transplantation; LDLT, living donor liver transplantation; LL, left liver; SV, splenic vein; HPS, hepatopulmonary syndrome; DDLT, deceased donor liver transplantation; LLS, left lateral section; PV, portal vein; IVC, inferior vena cava; HCC, hepatocellular carcinoma; RL, right liver; LRV, left renal vein. 
early liver retransplantation after multivisceral transplantation in a pediatric patient [15]. The use of a temporary PCS during LT operation can improve hemodynamic status and reduce intraoperative transfusion requirement. The interposed portal vein conduit connected to the superior mesenteric vein-splenic vein in an end-to-side fashion is useful to make a temporary PCS.

Using HBsAg-positive graft to HBV-naïve pediatric patient is one of the last choices to save a patient's life. We have experienced a few cases of LT using a HBsAg-positive graft in HBV-naïve adult patients with rapidly deteriorating conditions. Suppression of HBV replication was effectively achieved through oral antiviral agents in these patients. Preemptive HBV prophylaxis is mandatory following HBsAg-positive liver graft regardless of recipient's pretransplant HBV serologic status. Lamivudine is a low genetic barrier agent, thus it is vulnerable to the development of viral mutation. The primary reason why this patient is still administered with lamivudine is that lamivudine is known to be safe for children, and preemptive change to high genetic barrier agents such as entecavir and tenofovir is not currently permitted by the health insurance policy in Korea.

In conclusion, CAPV patients can have various vascular anomalies, thus combined vascular anomalies should be thoroughly assessed before and during LT operation. The most effective reconstruction techniques should be used to achieve satisfactory results following LT.

\section{ACKNOWLEDGMENTS}

\section{Conflict of Interest}

Shin Hwang is an editorial board member of the journal but did not involve in the peer reviewer selection, evaluation, or decision process of this article. No other potential conflicts of interest relevant to this article were reported.

\section{Funding/Support}

This study was supported by research grant from the Korean Society for Transplantation (2021-00-03001-009).

\section{ORCID}

Jung-Man Namgoong

https://orcid.org/0000-0002-9237-7440

Shin Hwang

Dae-Yeon Kim
Tae-Yong $\mathrm{Ha}$

Gi-Won Song

Dong-Hwan Jung

Kyung Mo Kim

Seak Hee Oh https://orcid.org/0000-0001-9932-0212 https://orcid.org/0000-0002-4235-0434 https://orcid.org/0000-0001-5984-023X https://orcid.org/0000-0001-7896-6751 https://orcid.org/0000-0002-9672-8877

\section{Author Contributions}

Conceptualization: SH. Data curation: JMN, KMK, SHO. Methodology: DYK, TYH, GWS, DHJ. Visualization: SH. Writing-original draft: $\mathrm{SH}, \mathrm{JMN}$. Writing-review \& editing: $\mathrm{SH}$.

\section{REFERENCES}

1. Shinkai M, Ohhama Y, Nishi T, Yamamoto H, Fujita S, Take $\mathrm{H}$, et al. Congenital absence of the portal vein and role of liver transplantation in children. J Pediatr Surg 2001;36:1026-31.

2. Sumida W, Kaneko K, Ogura Y, Tainaka T, Ono Y, Seo T, et al. Living donor liver transplantation for congenital absence of the portal vein in a child with cardiac failure. J Pediatr Surg 2006;41:e9-12.

3. Watanabe A. Portal-systemic encephalopathy in non-cirrhotic patients: classification of clinical types, diagnosis and treatment. J Gastroenterol Hepatol 2000;15:969-79.

4. Morgan G, Superina R. Congenital absence of the portal vein: two cases and a proposed classification system for portasystemic vascular anomalies. J Pediatr Surg 1994;29:1239-41.

5. Mistinova J, Valacsai F, Varga I. Congenital absence of the portal vein: case report and a review of literature. Clin Anat 2010;23:750-8.

6. Emre S, Arnon R, Cohen E, Morotti RA, Vaysman D, Shneider BL. Resolution of hepatopulmonary syndrome after auxiliary partial orthotopic liver transplantation in Abernethy malformation: a case report. Liver Transpl 2007;13:1662-8.

7. Hwang S, Kim DY, Ahn CS, Moon DB, Kim KM, Park GC, et al. Computational simulation-based vessel interposition reconstruction technique for portal vein hypoplasia in pediatric liver transplantation. Transplant Proc 2013;45:255-8.

8. Matsuura T, Soejima Y, Taguchi T. Auxiliary partial orthotopic living donor liver transplantation with a smallfor-size graft for congenital absence of the portal vein. 
Liver Transpl 2010;16:1437-9.

9. Law YM, Mack CL, Sokol RJ, Rice M, Parsley L, Ivy D. Cardiopulmonary manifestations of portovenous shunts from congenital absence of the portal vein: pulmonary hypertension and pulmonary vascular dilatation. Pediatr Transplant 2011;15:E162-8.

10. Uchida H, Sakamoto S, Shigeta T, Hamano I, Kanazawa $\mathrm{H}$, Fukuda A, et al. Living donor liver transplantation with renoportal anastomosis for a patient with congenital absence of the portal vein. Case Rep Surg 2012;2012:670289.

11. Gordon-Burroughs S, Balogh J, Weiner MA, Monsour HP Jr, Schwartz MR, Gaber AO, et al. Liver transplantation in an adult with adenomatosis and congenital absence of the portal vein: a case report. Transplant Proc 2014;46:2418-21.

12. Brasoveanu V, lonescu MI, Grigorie R, Mihaila M, Bacalbasa N, Dumitru R, et al. Living donor liver transplan- tation for unresectable liver adenomatosis associated with congenital absence of portal vein: a case report and literature review. Am J Case Rep 2015;16:637-44.

13. Li P, Hidaka M, Hamada T, Ikeda S, Ono S, Maruya $Y$, et al. Living donor liver transplantation for congenital absence of portal vein in portal venous reconstruction with a great saphenous vein graft. Surg Case Rep 2020;6:153.

14. Matsumoto N, Matsusaki T, Hiroi K, Kaku R, Yoshida R, Umeda $\mathrm{Y}$, et al. Pediatric living donor liver transplantation for congenital absence of the portal vein with pulmonary hypertension: a case report. Transplant Proc 2020;52:630-3.

15. Hwang S, Kim DY, Namgoong JM, Kim KM, Oh SH, Kim $\mathrm{KH}$, et al. Living donor liver retransplantation for primary non-function of liver graft following multivisceral transplantation in a pediatric patient. Ann Hepatobiliary Pancreat Surg 2020;24:198-202. 